\title{
HF2V Dissipator Effects on the Performance of a 3 Story Moment Frame
}

\author{
Tobias Bacht ${ }^{1}$, J. Geoffrey Chase ${ }^{1}$, Gregory MacRae ${ }^{2}$, Geoffrey W. Rodgers ${ }^{1}$, \\ Timon Rabczuk ${ }^{1}$, Rajesh P. Dhakal ${ }^{2}$, Jonathan Desombre ${ }^{1}$ \\ ${ }^{1}$ Department of Mechanical Engineering, University of Canterbury, University of Canterbury, Private Bag 4800, \\ Christchurch 8140, New Zealand \\ ${ }^{2}$ Department of Civil Engineering, University of Canterbury, University of Canterbury, Private Bag 4800, \\ Christchurch 8140, New Zealand
}

\begin{abstract}
In this paper, the seismic performance of the as-designed SAC Los Angeles 3 storey seismic frame with rigid moment connections at the beam ends is compared with that of the same frame using semirigid connections with high force-to-volume (HF2V) lead dissipators. The presence of the gravity frames in the model is also considered. It was found that the placement of dissipators, ignoring the effect of the gravity frames, caused a $12 \%$ increase in period of the frame due to the decreased stiffness of the connections. During design level ground shaking the semi-rigid connections with HF2V dissipators have slightly lower accelerations, up to an $80 \%$ increase in peak drift, and a $200 \%$ increase in the permanent displacement compared to the asdesigned case, but no structural damage is expected. When the gravity frames are considered, the floor accelerations decrease further, the peak displacements do not significantly change, but the residual storey dirft ratios reduce to approximately $0.17 \%$. This result is less than one half that of the as-designed frame, where typically gravity frame effects are not considered. The realistic analyses combining HF2V lead dissipators with gravity frames and well-designed non-structural elements creates a system with almost no structural damage and low residual displacements.
\end{abstract}




\section{Introduction}

Where steel moment frame structures are expected to be exposed to moderate or strong earthquakes, they are designed to accept damage in the beam end plastic hinge zones or in the beam-column joint panel zones. Furthermore, large permanent displacements may be present at the end of the earthquake shaking. Repair costs for such damage and consequent downtime can be substantial to the building owners and users, creating significant economic and business impacts.

The use of a Damage Avoidance Design approach (DAD) (Mander and Cheng 1997) approach, with relatively damage-free connections, reduced repairs, and minimized disruption would substantially reduce economic and business impacts. Damage avoidance may be achieved in moment frames by using special devices that do not show degradation of dissipative performance with use. Ideally, such devices would perform in a consistent and repeatable manner on every response cycle throughout the life of a structure, and would not require maintenance or replacement after a seismic event.

Energy dissipation devices using lead were proposed by Robinson and Greenbank (1976) to absorb energy in a controlled, repeatable manner as a base isolation system. Lead is ideal for this purpose due to its unique rheological properties, low recrystallisation temperature, and ability to allow any residual compression forces in the device to creep back towards zero over time (Rodgers et al. 2008b). Prototype devices of $100-700 \mathrm{kN}$ capacity have been used in several bridges and buildings in New Zealand (Skinner et al. 1993). A summary of the state of the practice that developed 
from this early work is given by Cousins and Porritt (1993). While these devices were ideal for their intended purpose, they were too large to fit within standard structural connections, despite having the necessary resisting force and energy dissipation capacity.

Recently developed high force-to-volume (HF2V) dissipation devices of compact size (Rodgers et al. 2007) can fit directly into beam-column connections to enable true damage avoidance connections. The device consists of a steel cylinder filled with lead and through which a shaft with a bulge passes. As the shaft is moved, the lead moves around the bulge providing a resisting force. These devices may be modelled as weakly velocity sensitive non-linear viscous dampers, whereby, at higher velocities, a slightly greater resisting force is provided. The relationship between velocity and damper force, $F_{\text {Damper }}$, is defined in (Pekcan et al. 1999):

$$
F_{\text {Damper }}=C_{\alpha} \dot{x}^{\alpha}
$$

where $C_{\alpha}=$ a constant dependent on specific device geometry, $\dot{x}=$ the velocity of the damper shaft relative the casing, and $\alpha=$ the velocity exponent, which is within the range of 0.11-0.15 (Rodgers et al. 2008a), and taken as 0.12 in this study (Cousins and Porritt 1993).

The HF2V devices are relatively inexpensive to manufacture and they have been experimentally characterized, with full details shown by Rodgers et al. (2007). Energy can be dissipated on every successive dynamic response cycle without strength degradation or permanent damage (Rodgers et al. 2008b), in contrast to conventional steel connections or connections with sacrificial dissipators (Bradley et al. 2008; Li 
2006). These attributes, and the low cost, make them potentially economically feasible for wide use in large buildings where a damage-free response is desired. Figure 1a shows a picture of a $120 \mathrm{kN}$ capacity prototype device.

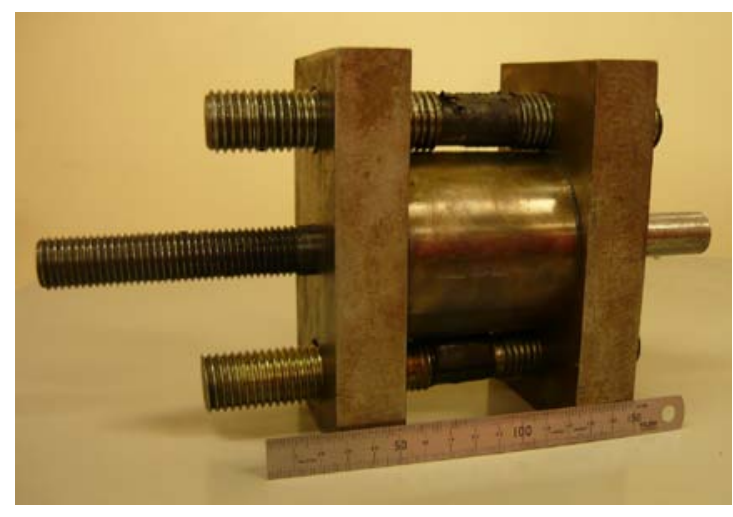

(a) Device with mounting bolts

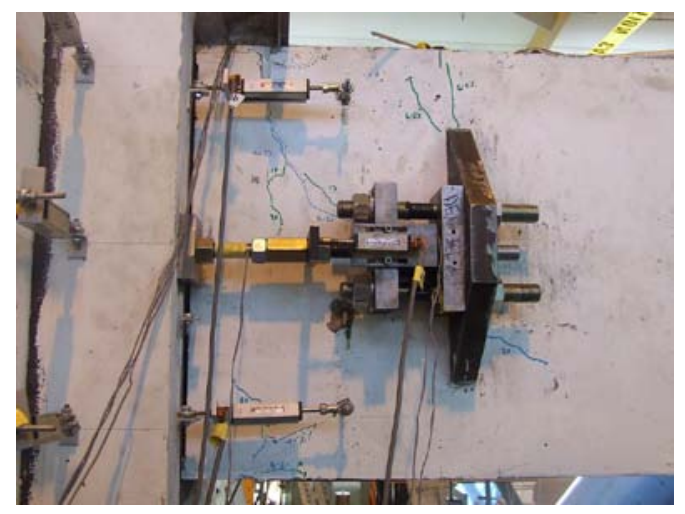

(b) In Concrete DAD Connection

Figure 1: Cylindrical 120 kN HF2V Device Use

Figure $1 \mathrm{~b}$ shows a $120 \mathrm{kN}$ prototype device and mounting brackets externally placed on an $80 \%$ full size prestressed concrete connection (Rodgers et al. 2008b). In addition to these experimental studies, spectral analysis has led to the development of performance-based design guidelines to characterize their impact on seismic response over suites of ground motion records (Rodgers et al. 2008a).

To address the performance of steel moment frames, it is necessary to answer the following questions:

1) Can HF2V devices be used in steel frames?

2) Can these devices in steel joints be modelled appropriately?

3) Are there ways to minimize permanent displacements of the structure?

4) How does the response change when using these devices, instead of conventional connections, in modern steel moment resisting frames? 
In an attempt to address and answer these questions, this paper conducts several nonlinear dynamic analyses to compare the seismic performance of a structure with and without the HF2V devices. The structure analysed is the SAC Steel Project three story steel moment resisting frame designed for Los Angeles. Floor accelerations, peak story drifts and permanent story drifts are the parameters that will be used to describe the need of cost- and time-intensive structural repairs.

\section{Application of HF2V Devices in Steel Buildings}

A simple device model with low computational cost is required to consider these devices in large non-linear dynamic simulations. The HF2V joint connection design to be modelled is shown in Figure 2 for an experimental 50\% scale steel beam column connection used to investigate device properties and their impact on hysteretic steel connection behaviour (Desombre et al. 2011; Mander et al. 2009). The beam end is cut at an angle of 0.1 radians to provide space for joint rotational motion to be transmitted to the device. The upper flange is connected to the column by means of an angle bracket and bolts, effectively hinged at the top edge to form a semi-rigid connection. Both axial and shear force is considered to be carried by this connection.

The device is connected above or below the beam bottom flange and the end of the shaft passing through the device is connected to the column flange. The eccentricity between the top-flange rocking connection and the damper line of action is an important consideration in design. An increase in eccentricity will lead to increased lateral resistance and increased frame stiffness for a given damper size. Alternatively, the required damper capacity is reduced for a given frame resistance by increasing the 
damper eccentricity, although the required stroke capacity of the damping device is increased accordingly.

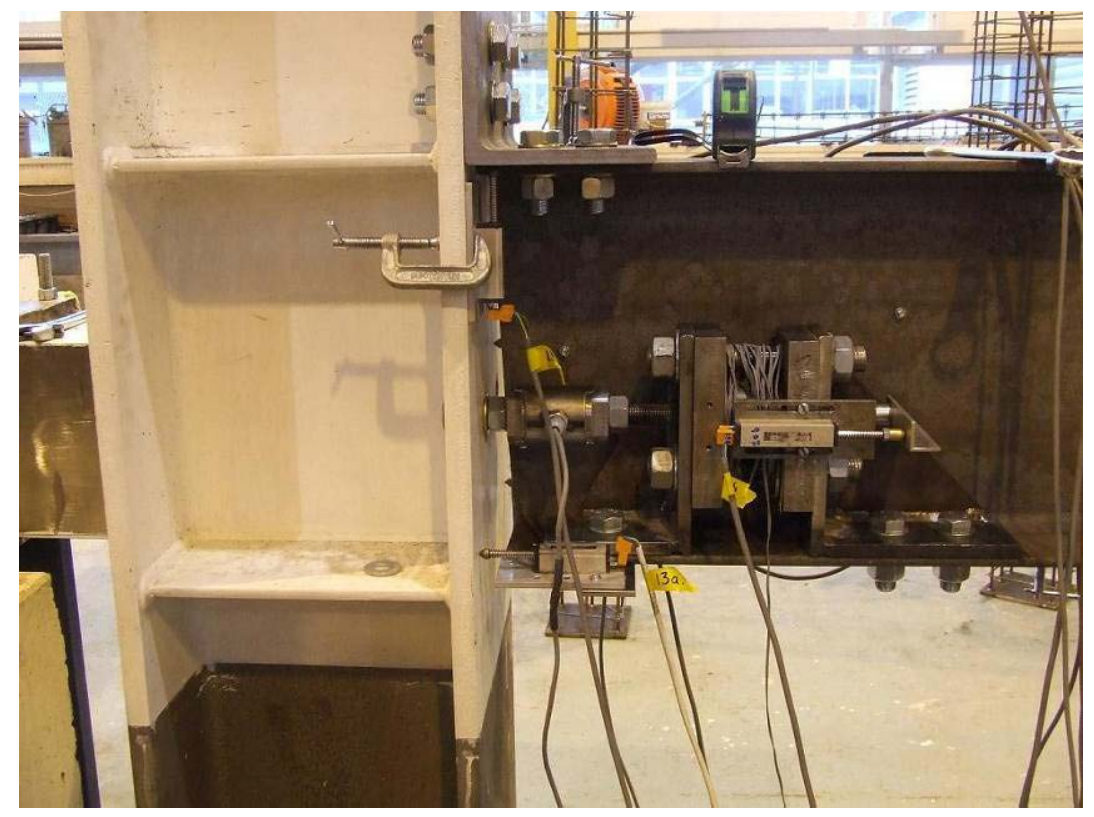

Figure 2: Steel Joint with HF2V Device Setup

\section{Modelling HF2V Devices in Steel Buildings}

The experimental setup in Figure 2 was modelled in detail with separate consideration of the device, beam, column and the pinned connection on the top of the beam. It was carried out using the finite element program ABAQUS. While this model allowed the connection behaviour to be appropriately modelled, a simpler model was desired for multiple time history analyses of a multi-storey building with many connections. A rotational hinge element, containing elastic, plastic and velocity dependent (damping) components, was therefore developed.

A comparison between the experimental data from the test in Figure 2 and that from the simple hinge model developed is shown in Figure 3 (Desombre et al. 2011). Note 
that the experimental results in Figure 3 have multiple cycles to $4 \%$ drift without any notable stiffness or strength degradation (Mander et al. 2009). Moderate differences between the experimental and model results can be seen at large increasing story drifts, where the experimental results have a positive slope and the model results have a negative slope. Two main factors attribute to this difference. First, the flexibility of the damper connecting elements result in a lag effect between the velocity of the column/connection rotation and the velocity induced within the damping device. Second, the damper moves in an arc about the rocking edge, but is only designed to allow linear translational motion. Therefore, at large drifts there is some additional friction and low level binding of the damper shaft against the endcaps. This additional friction results in a slight bi-linear response of the damping device and is the main reason for the positive slope of the experimental hysteresis loop. Due to the fact that the model does not incorporate these secondary effects, there is a small but notable difference in the results at large drifts. The model was considered to be sufficiently reliable for incorporation in the building model in this research.

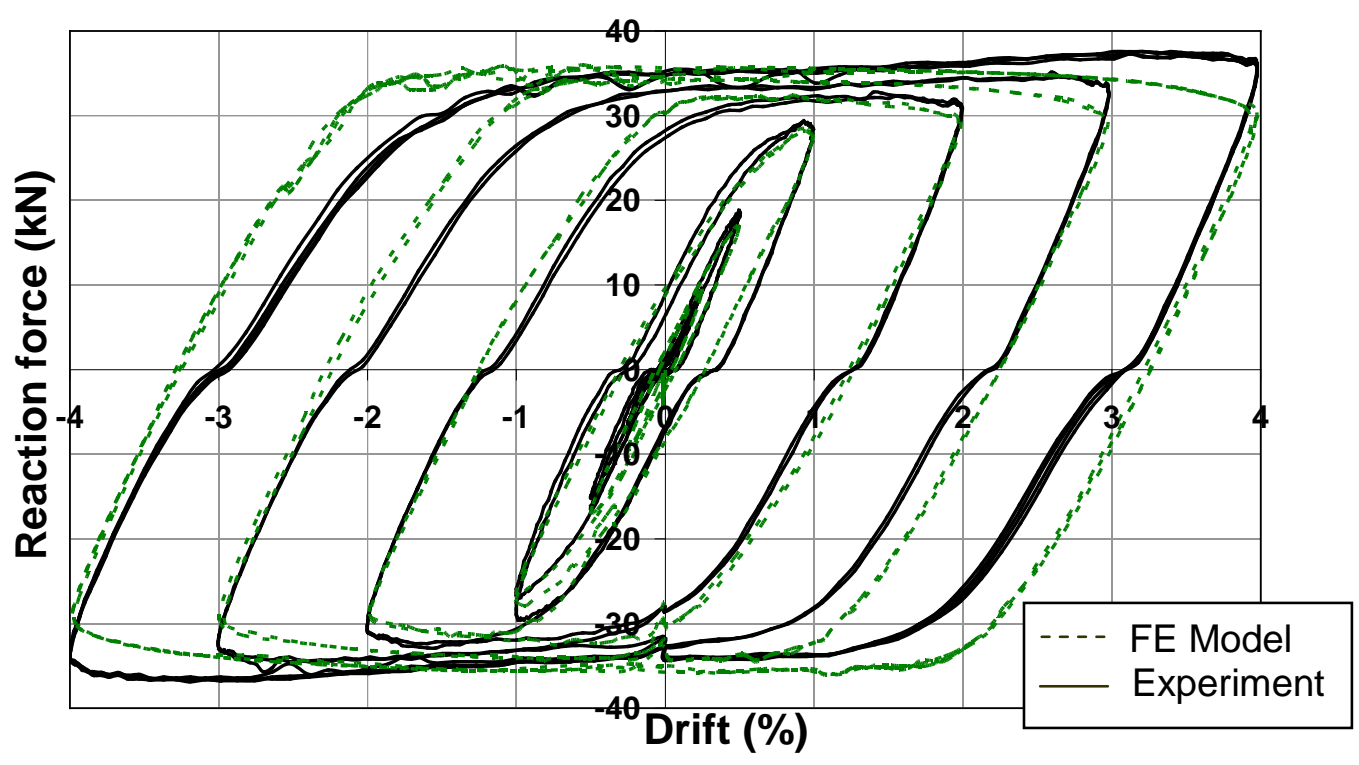

Figure 3: Finite Element Hinge Model Comparison with Experiment 


\section{Minimizing Permanent Displacements}

The HF2V devices exhibit behaviour similar to that from an elastic perfectly plastic (EPP) structure as shown in Figure 3. If this device is placed in a real structure, Pdelta effects on the frame are likely to cause the curve to have a negative post-elastic stiffness ratio, $r$, where $r$ is shown schematically in Figure 4a. Single-degree-offreedom (SDOF) oscillators with $r \leq 0$ have little inherent dynamic re-centering capability, as shown by the average residual displacement ratio, $\Delta_{r} / \Delta_{r, \max }$, in Figure 4b, where $\Delta_{r}$ is the residual displacement and $\Delta_{r, \max }$ is the maximum possible residual displacement for the specified target ductility (MacRae and Kawashima 1997). Because of the shape of the hysteresis curve, it is likely that even if no damage to the structure or contents occurs, the structure may have large permanent displacements that will make it vulnerable to aftershocks and difficult to straighten after an earthquake.
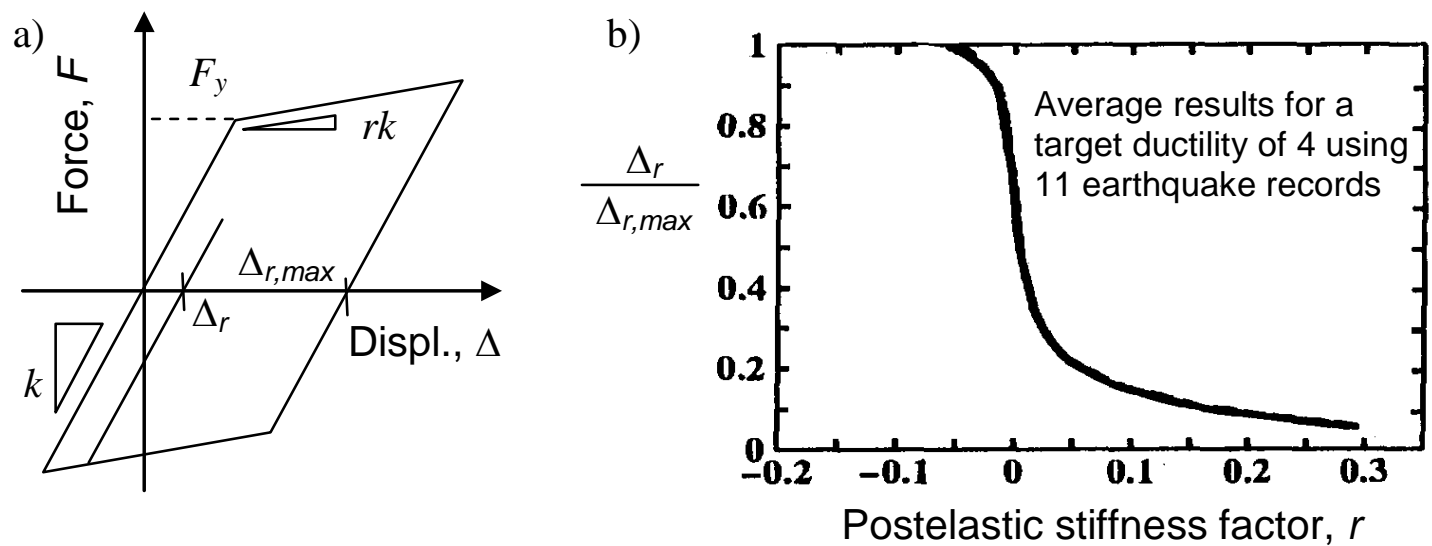

Figure 4. Effect of Hysteresis Curve on Residual Displacement Ratio: a) Schematic Hysteresis curve, and b) Average Residual Displacement Ratio (Kawashima et al. 1998) 
It may be seen from Figure 4 that one means of improving the likely response is to increase the post-elastic stiffness factor, $r$, until it is significantly positive. Another method in multi-storey frames is to consider the effect of continuous columns over the height of the structure. Such columns, which include the seismic in-plane columns, the seismic out-of-plane columns and all gravity columns, provide continuity between stories. Thus, the response of the overall frame is not like that of the SDOF oscillators in Figure 4. In fact, MacRae et al. (2004) have shown that continuous columns reduce the drift concentrations in individual stories. Also, Tagawa et al. (2007) have shown that for multi-storey steel frames, where individual stories have a negative post-elastic stiffness, the instantaneous post-elastic stiffness ratio, $r_{i}$, was always greater than zero during records causing major yielding due to the presence of continuous columns. In dynamic analyses conducted by researchers or practitioners, the effect of column continuity is often not considered, except in the seismic frame analyzed, and gravity frame effects are thus often ignored. Based on these results, large permanent displacements may be mitigated by either increasing the post-elastic stiffness of each story, or by providing/considering column continuity.

While post-elastic stiffness of the HF2V device is close to zero, the post-elastic stiffness of the total storey in a steel frame may be greater than zero primarily as a result of the rotational stiffness of the gravity beam end connections. This added stiffness contribution, which can be controlled to some extent in the design and is in addition to the contribution of column continuity, is investigated in this research.

\section{Frames Analyzed}




\section{(a) Frame Selection}

The structural system used in this investigation was developed as part of the Los Angeles SAC Steel Project (Krawinkler and Gupta 1998). The SAC Project was primarily concerned with the impact of connection fractures of steel moment resisting frames in nine buildings, with three, nine and twenty storeys designed for Los Angeles, Seattle and Boston locations. The structure and earthquake suite used in this research were developed for the Los Angeles area (Somerville et al. 1997), whose high level of seismic hazard makes it a good candidate for implementation of the DAD connections with HF2V devices.

The specific structure in this study is the three-storey steel building designed for Los Angeles, also called SAC-3 or LA-3, with moment resisting frames only at the periphery. Each bay has centreline dimensions of $9.14 \mathrm{~m}$ by $9.14 \mathrm{~m}$ and the columns extend over the 3 stories of $3.96 \mathrm{~m}$ height each. Figure 5 shows the typical floor plan. The structure is nearly uniform in the two orthogonal directions. The horizontal seismic weight per frame at levels 3,2 and 1 were $5200 \mathrm{kN}, 4800 \mathrm{kN}$ and $4800 \mathrm{kN}$ respectively.

For the two-dimensional analyses, only the east half of the building is modelled, as shown in Figure 5. The seismic frame is modelled directly, but to further reduce the total number of degrees of freedom, the other columns on the east half of the building are merged into a single "consolidated gravity column" (Axis E) by summing the stiffness and strength of the individual columns considering deformation in the N-S direction. The consolidated gravity column is slaved in the horizontal direction at every floor to the seismic frame to form a complete two-dimensional model shown in 
Figure 6. Pins at the ends of the beams in the right hand bay represent perfectly pinned connections. With these pinned connections, the bay width in the right hand bay is unimportant. However, this width was assumed to be one half of the actual bay width for convenience in different case studies, as discussed later.

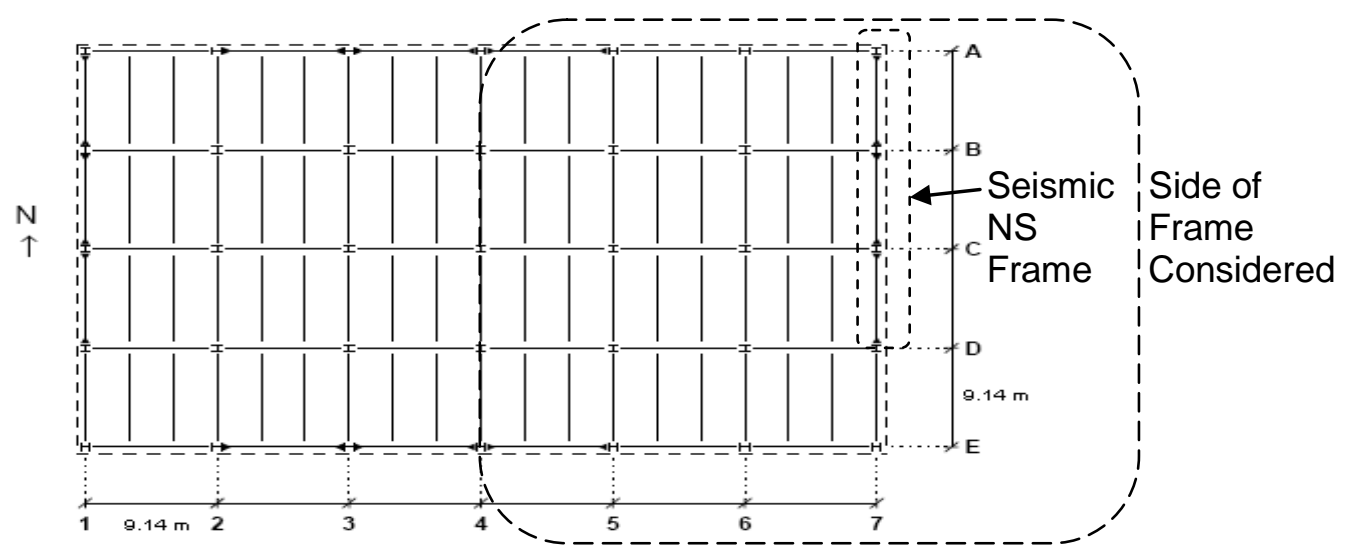

Figure 5: SAC-3 typical floor plan (Luco 2002)

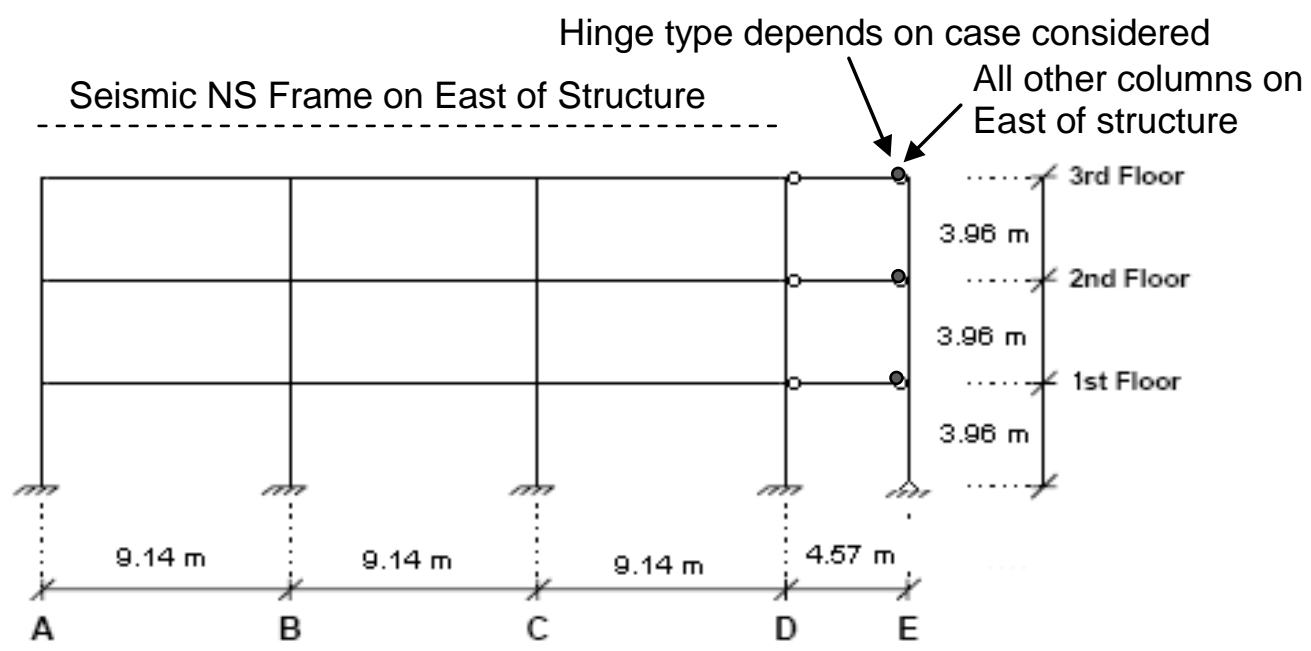

Figure 6: Model 1 - As-Designed Structure

The second and third models considered, Model 2 and Model 3, used HF2V devices in the seismic frame, rather than the as-designed rigid beam-column connections. These modified connections are shown as rectangular boxes between grid lines A - D of Figure 7. As a result, it is expected that this change in connection design will affect the structural stiffness and natural period as well as its ability to dissipate energy. 


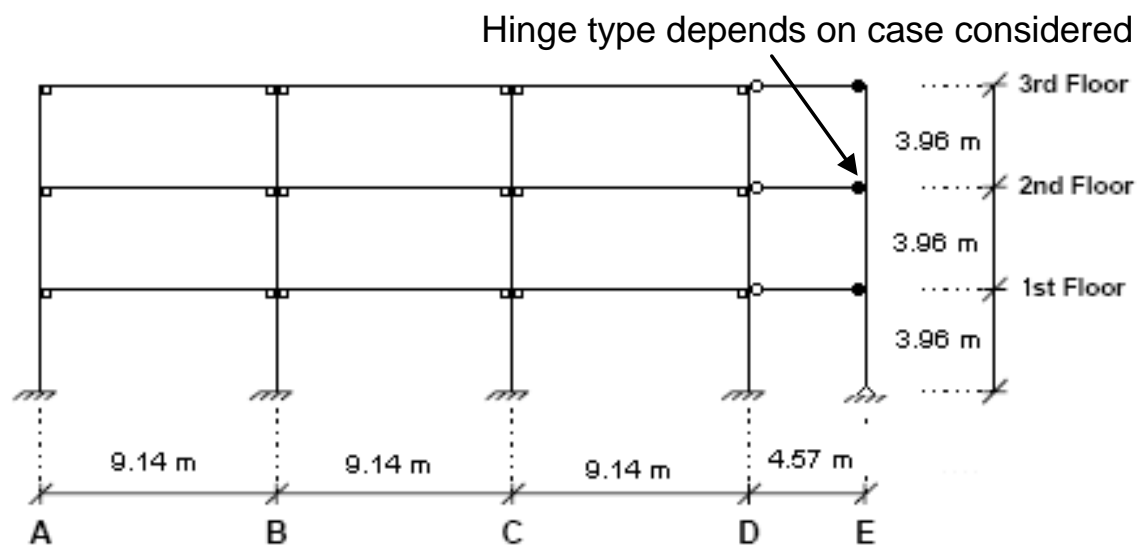

Figure 7: Models 2 and 3 - With Devices in the Seismic Frame

The HF2V device force capacity is chosen to achieve the base shear strength required by FEMA 450 (2003). The seismic base shear was determined by Equation (2) where $C_{s}$ is the seismic coefficient and $W$ is the structure's seismic weight.

$$
V=C_{S} W
$$

where $C_{s}$ was determined by Equation (3), $S_{D S}=$ the design spectral response acceleration parameter, $R=$ the response modification factor and $I=$ the occupancy importance factor.

$$
C_{S}=S_{D S} /(R / I)
$$

For the Los Angeles area, soil type $D$, an $R$ factor of 8 , and a period, $T$, of $1.0 \mathrm{~s}$, means $C_{s}=0.05$. Hence, the design strength for this structure is $5 \%$ of its seismic weight. Model 2 was provided with devices that allowed this base shear value to be reached. 
Due to the possibility of overstrength, and to have a more reasonable comparison with Model 1, Model 3 was designed to resist twice this base shear, or $10 \%$ of the total weight. In both Models 2 and 3, device capacities were thus selected such that the shear resistances at each level over the seismic frame height were proportional to the weight above.

For each of the seismic frame models, Models 1-3, three separate cases for the gravity beam end connection rotational stiffness and strength were considered. Parameters describing the bilinear beam end rotation stiffness and strength values were provided beside Column E. These parameters are given in Table 1.

- Case 1 represents the case of a perfect pin with no rotational stiffness $(k=0)$.

- Case 2 describes much less effective connection with $k=1.7 E I / L$ and $M_{s}$ of $50 \%$ of $M_{p}$

- Case 3 describes a major effect of the gravity beam (and slab) end connection, where the rotational stiffness, $k=2.5 E I / L$ and the strength, $M_{s}$, is $100 \%$ of the plastic moment of the beam, $M_{p}$.

The values chosen in Cases 1 and 2 are based on previously published experimental studies (Liu and Astaneh-Asl 2000; Liu and Astaneh-Asl 2004). In the span D-E beam, the point of inflection in the gravity beams is $4.57 \mathrm{~m}$ from Column $\mathrm{E}$, which is the expected location of the point of inflection due to seismic forces. This point is shown by the white circles representing perfect pins on the right of column $\mathrm{D}$ in Figures 6 and 7. 
The different models (representing the seismic frame characteristics) and the different cases (representing the gravity beam end connection bilinear parameters) are given in Table 1. Model 1 Case 1 (M1C1) represents the SAC LA3 building design as it is generally analyzed with no extra consideration for gravity frame effects. The fundamental periods varied from 1.0s for M1C1 to 1.12s for M3C1. Initial stiffness proportional Rayleigh damping of $5 \%$ was used in the first mode. Velocity dependence of the device dissipation was incorporated into the modelling following Equation (1) (Desombre et al. 2011).

Table 1: Analysis Matrix

\begin{tabular}{|c|c|c|c|}
\hline Model & Model Characteristics & Case & $\begin{array}{c}\text { Gravity Beam End } \\
\text { Connection for Case }\end{array}$ \\
\hline & As- designed & 1 & $k=0$ \\
1 & seismic frame & 2 & $k=1.7 E I / L, M_{s}=50 \% M_{p}$ \\
& With HF2V Devices - & 1 & $k=2.5 E I / L, M_{s}=100 \% M_{p}$ \\
\hline & Design Base Shear is 5\% of & 2 & $k=1.7 E I / L, M_{s}=50 \% M_{p}$ \\
2 & Weight & 3 & $k=2.5 E I / L, M_{s}=100 \% M_{p}$ \\
\hline & With HF2V Devices - & 1 & $k=0$ \\
& Design Base Shear is 10\% of & 2 & $k=1.7 E I / L, M_{s}=50 \% M_{p}$ \\
3 & Weight & 3 & $k=2.5 E I / L, M_{s}=100 \% M_{p}$ \\
\hline
\end{tabular}

Dynamic inelastic time history analyses were conducted with ABAQUS using the LA medium suite of the earthquake records from the SAC Steel Project (Somerville et al. 1997). These 20 earthquake records have a magnitude between 6.5 - 7.25, epicentral distances of 5 - 40 kilometres and an exceedance probability of $10 \%$ in 50 years, which equates to a return period of 475 years. They are probabilistically scaled to match the design spectrum for the Los Angeles region and they are therefore design basis earthquakes (DBE). 


\section{(b) Frame Behaviour}

The total floor accelerations, relative residual roof drifts and relative storey drifts are listed in Tables 2 to 4 . In each case, the median ( $50^{\text {th }}$ percentile) and appropriate lognormal standard deviation (Limpert et al. 2001) are calculated based on the 20 data points. The log-normal geometric mean (or median) $\hat{x}$, based on $n$ samples, $x_{i}$, is defined:

$$
\hat{x}=\exp \left(\frac{1}{n} \sum_{i=1}^{n} \ln \left(x_{i}\right)\right)
$$

Similarly, the log-normal-based multiplicative standard deviation, $\hat{\sigma}$, is defined:

$$
\hat{\sigma}=\exp \sqrt{\frac{1}{n-1} \sum_{i=1}^{n}\left(\ln \left(x_{i} / \hat{x}\right)\right)^{2}}
$$

It is important to note that when using the multiplicative standard deviation as defined in Equation (5), the range of one standard deviation, covering on average $68 \%$ of the data values, is defined as between $\hat{x} / \hat{\sigma}$ and $\hat{x} \times \hat{\sigma}$. The range for two standard deviations, covering on average $95 \%$ of the data values, is between $\hat{x} /\left(\hat{\sigma}^{2}\right)$ and $\hat{x} \times\left(\hat{\sigma}^{2}\right)$. Finally, three standard deviations covers the range from $\hat{x} /\left(\hat{\sigma}^{3}\right)$ to $\hat{x} \times\left(\hat{\sigma}^{3}\right)$. It should be noted that this definition varies from that used for normal distribution and is the reason that some of the smaller median values presented in Tables 2-4 (such as Interstory Drift) have seemingly large values for the deviation. 
Table 2: Response for Gravity Beam End Connection Case $1(\mathrm{k}=0)$ showing the median, multiplicative deviation and percentage change.

\begin{tabular}{|c|c|c|c|c|c|c|c|c|c|}
\cline { 3 - 9 } \multicolumn{2}{c|}{} & \multicolumn{2}{c}{ Model 1 } & \multicolumn{3}{c|}{ Model 2 } & \multicolumn{3}{c|}{ Model 3 } \\
\cline { 3 - 10 } \multicolumn{2}{c|}{} & \multicolumn{2}{c|}{ As built } & \multicolumn{3}{c|}{ 5 \% Baseshear } & \multicolumn{3}{c|}{ 10 \% Baseshear } \\
\cline { 3 - 10 } \multicolumn{2}{c|}{} & median & deviation & median & deviation & change [\%] & median & deviation & change [\%] \\
\hline Peak Acc Floor 1 & {$\left[\mathrm{m} / \mathrm{s}^{\wedge} 2\right]$} & 8.062 & 1.640 & 7.580 & 1.597 & -6.362 & 7.423 & 1.618 & -8.613 \\
Peak Acc Floor 2 & {$\left[\mathrm{m} / \mathrm{s}^{\wedge} 2\right]$} & 6.892 & 1.535 & 5.437 & 1.668 & -26.767 & 5.412 & 1.665 & -27.341 \\
Peak Acc Floor 3 & {$\left[\mathrm{m} / \mathrm{s}^{\wedge} 2\right]$} & 8.250 & 1.483 & 5.772 & 1.534 & -42.938 & 5.626 & 1.535 & -46.636 \\
\hline Relative Roof Drift & {$[\mathrm{m}]$} & 0.185 & 1.916 & 0.359 & 1.430 & 94.295 & 0.327 & 1.413 & 76.582 \\
Residual Roof Drift & {$[\mathrm{m}]$} & 0.039 & 2.657 & 0.120 & 2.366 & 207.088 & 0.067 & 5.787 & 70.848 \\
\hline Interstorey Drift 3-2 & {$[\mathrm{m}]$} & 0.075 & 1.353 & 0.133 & 1.380 & 77.848 & 0.122 & 1.357 & 63.188 \\
Interstorey Drift 2-1 & {$[\mathrm{m}]$} & 0.070 & 1.383 & 0.122 & 1.435 & 73.323 & 0.111 & 1.411 & 58.646 \\
Interstorey Drift 1-0 & {$[\mathrm{m}]$} & 0.068 & 1.357 & 0.110 & 1.444 & 60.480 & 0.089 & 1.684 & 30.430 \\
\hline
\end{tabular}

Table 3: Response for Gravity Beam End Connection Case 2 ( $k=1.7 \mathrm{EI} / \mathrm{L}, \mathrm{M}_{\mathrm{pl}}=50 \%$ ) showing the median, multiplicative deviation and percentage change.

\begin{tabular}{|c|c|c|c|c|c|c|c|c|c|}
\hline & \multirow{2}{*}{\multicolumn{2}{|c|}{$\begin{array}{l}\text { Model } 1 \\
\text { As built }\end{array}$}} & \multirow{2}{*}{\multicolumn{3}{|c|}{$\begin{array}{c}\text { Model } 2 \\
\text { Baseshear }\end{array}$}} & \multirow{2}{*}{\multicolumn{3}{|c|}{ Model 3}} \\
\hline & & & & & & & & & \\
\hline & & median & deviation & median & deviation & change $[\%]$ & median & deviation & change $[\%]$ \\
\hline Peak Acc Floor 1 & {$\left[\mathrm{~m} / \mathrm{s}^{\wedge} 2\right]$} & 7.874 & 1.665 & 7.379 & 1.624 & -6.716 & 7.228 & 1.643 & -8.950 \\
\hline Peak Acc Floor 2 & {$\left[\mathrm{~m} / \mathrm{s}^{\wedge} 2\right]$} & 6.837 & 1.526 & 5.689 & 1.653 & -20.169 & 5.582 & 1.610 & -22.475 \\
\hline Peak Acc Floor 3 & {$\left[\mathrm{~m} / \mathrm{s}^{\wedge} 2\right]$} & 8.645 & 1.447 & 6.094 & 1.534 & -41.866 & 5.940 & 1.511 & -45.532 \\
\hline Relative Roof Drift & [m] & 0.194 & 1.370 & 0.306 & 1.380 & 57.301 & 0.280 & 1.387 & 44.105 \\
\hline Residual Roof Drift & [m] & 0.015 & 4.408 & 0.022 & 2.934 & 40.491 & 0.020 & 2.273 & 30.161 \\
\hline Interstorey Drift 3-2 & $\overline{[\mathrm{m}]}$ & 0.069 & 1.353 & 0.114 & 1.289 & 65.711 & 0.104 & 1.310 & 51.940 \\
\hline Drift 2-1 & [m] & 0.066 & 1.367 & 0.104 & 1.378 & 58. & 0.095 & 1.384 & 45.344 \\
\hline Interstorey Drift 1-0 & [m] & 0.067 & 1.350 & 0.097 & 1.342 & 45.064 & 0.088 & 1.359 & 32.319 \\
\hline
\end{tabular}

Table 4: Response for Gravity Beam End Connection Case 3 ( $\left.\mathrm{k}=2.5 \mathrm{EI} / \mathrm{L}, \mathrm{M}_{\mathrm{pl}}=100 \%\right)$ showing the median, multiplicative deviation and percentage change.

\begin{tabular}{|c|c|c|c|c|c|c|c|c|c|}
\cline { 3 - 9 } \multicolumn{2}{c|}{} & \multicolumn{2}{c}{ Model 1 } & \multicolumn{3}{c|}{ Model 2 } & \multicolumn{3}{c|}{ Model 3 } \\
\cline { 3 - 10 } \multicolumn{2}{c|}{} & \multicolumn{2}{c|}{ As built } & \multicolumn{3}{c|}{$\mathbf{5 \% \text { Baseshear }}$} & \multicolumn{3}{c|}{ 10 \% Baseshear } \\
\cline { 3 - 10 } \multicolumn{2}{c|}{} & median & deviation & median & deviation & change [\%] & median & deviation & change [\%] \\
\hline Peak Acc Floor 1 & {$\left[\mathrm{m} / \mathrm{s}^{\wedge} 2\right]$} & 7.841 & 1.525 & 7.315 & 1.633 & -7.192 & 7.170 & 1.609 & -9.357 \\
Peak Acc Floor 2 & {$\left[\mathrm{m} / \mathrm{s}^{\wedge} 2\right]$} & 6.791 & 1.434 & 5.722 & 1.634 & -18.689 & 5.595 & 1.620 & -21.377 \\
Peak Acc Floor 3 & {$\left[\mathrm{m} / \mathrm{s}^{\wedge} 2\right]$} & 8.738 & 1.480 & 6.071 & 1.543 & -43.923 & 5.953 & 1.510 & -46.776 \\
\hline Relative Roof Drift & {$[\mathrm{m}]$} & 0.193 & 1.367 & 0.296 & 1.383 & 53.576 & 0.272 & 1.399 & 41.343 \\
Residual Roof Drift & {$[\mathrm{m}]$} & 0.015 & 4.832 & 0.021 & 3.306 & 43.479 & 0.019 & 3.444 & 29.323 \\
\hline Interstorey Drift 3-2 & {$[\mathrm{m}]$} & 0.067 & 1.362 & 0.110 & 1.291 & 65.111 & 0.101 & 1.319 & 51.888 \\
Interstorey Drift 2-1 & {$[\mathrm{m}]$} & 0.065 & 1.362 & 0.101 & 1.380 & 56.059 & 0.093 & 1.395 & 43.738 \\
Interstorey Drift 1-0 & {$[\mathrm{m}]$} & 0.066 & 1.352 & 0.094 & 1.341 & 41.970 & 0.086 & 1.373 & 30.037 \\
\hline
\end{tabular}


As seen in Tables 2-4, the total floor accelerations were between $6 \%$ and $46 \%$ less for the structures with HF2V devices (Models 2 and 3) compared to the as-designed structure (Model 1). The greatest reduction occurred in the upper stories. Accelerations for the 5\% and 10\% base shear cases (Models 2 and 3) were similar, as were the lognormal standard deviations.

The similar lognormal deviations indicate that the HF2V design did not change the distribution of the responses. The reductions in total storey accelerations should significantly increase occupant and contents safety. The bigger damping and the increase in period are reasons for reduced accelerations in the stronger frame (Rodgers et al. 2008a).

The median increase in peak storey drift is between $30 \%$ and $78 \%$; this can be attributed to the increased period. This increase is greatest in Model 2 (with 5\% base shear) for Case 1 where gravity frame effects are ignored because there is no added recentering stiffness to resist the motion. The experimental investigation of this technology presented in Mander et al. (2009) shows that repeated cycles to $4 \%$ drift can be undertaken without any stiffness or strength degradation. Therefore, no damage to structural connections is expected with the HF2V devices in the seismic frame (Models 2-3). Nevertheless, the increase in storey drifts may incur damage to poorly detailed non-structural elements, such as cladding and internal partitions. However, if the non-structural elements are designed and detailed to sustain these larger (but not unrealistic) drifts without damage, then no non-structural damage is expected. 
The median relative roof drifts are increased by $35 \%$ to $94 \%$, which is similar to the increase in drifts. Figure 8 shows the relative roof displacement for the Loma Prieta earthquake record in the medium suite and compares the Model 1 Case 2 response to that of the Model 2 (5\% base shear) Case 2 response. It can be clearly seen that the peak displacement is significantly higher for the $5 \%$ base shear design structure.

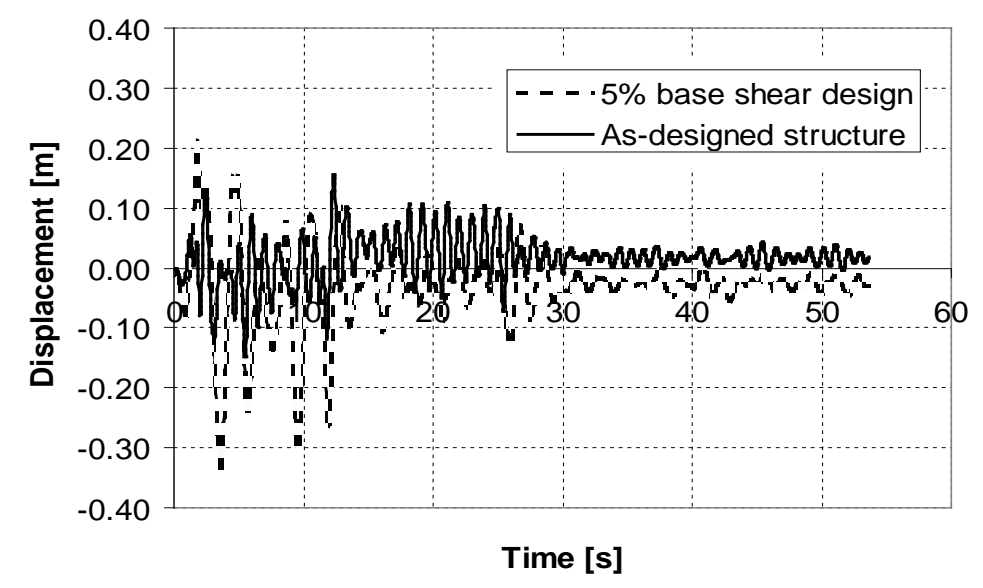

Figure 8: Relative Roof Displacement History for LA01 and k=1.7EI/L

The presence of the HF2V devices (Models 2 and 3) increased the median relative roof residual (or permanent) displacement by more than 200\% for the Case 1 frame (with $\mathrm{k}=0$ at all gravity beam ends). However, for the frames with the gravity beam end connection stiffness and strength considered, the median increase was less than $50 \%$.

Even though the peak displacements of the models containing dissipators, Models 2 and 3 , are more than twice that of the as-designed (Model 1 , i.e. $\mathrm{k}=0$ ) structure, the presence of the gravity frame stiffness and strength (i.e. Cases 2 and 3) decreases the residual displacement to about one half of that of the as-designed $(\mathrm{k}=0)$ structure. The median value of the relative residual roof drifts for the frames with devices when 
considering the gravity frames was less than $0.22 \%$. This is close to the allowable construction tolerance of $0.2 \%$. Hence, designing recentering stiffness into gravity frame connections enables reduced permanent displacement despite damage-free increased transient response.

The distribution of residual drifts is much tighter for the structures considering gravity columns and their recentering stiffness. For example, the $95^{\text {th }}$ percentile residual drift for Models 1, 2 and 3 were $0.039 \mathrm{~m} * 2.657^{2}=0.275 \mathrm{~m}, 0.671 \mathrm{~m}$, and $2.243 \mathrm{~m}$ for the Case $1(\mathrm{k}=0)$ frame, but it is $0.291 \mathrm{~m}, 0.189 \mathrm{~m}$ and $0.103 \mathrm{~m}$ for the Case 2 frames. The combination of HF2V dissipators with the gravity frame stiffness is therefore very effective and a higher level of confidence can be ascertained to the performance of structures designed with these devices.

\section{CONCLUSIONS}

This paper has explored the advanatges of using HF2V energy dissipators at the beam column joints of steel moment resisting frames by analysing the SAC Los Angeles 3 storey seismic frame subject to the SAC Los Angeles medium suite records. It has incorporated recentering stiffness both from the gravity columns and from the beam connection to gravity columns together with DAD connections using HF2V devices. It has been shown that:

i) Placing HF2V lead dissipators in the seismic frame joints reduces the joint stiffness and increases the fundamental period, resulting in decreased floor accelerations, increased peak displacements and slightly increased residual 
displacements with respect to those obtained from the as-designed rigid jointed frame. Due to the fact that median interstory drifts for Models 2 and 3 get as high as $3 \%$, the effects of these drifts on the gravity frame and non-structural elements must be considered. Careful detailing to prevent the gravity frame carrying lateral loads and well-designed and separated non-structural elements are needed to prevent an increase in non-structural damage from this design approach. No damage is expected to the core seismic frame because all energy dissipation and non-linearity occurs in the damage free HF2V devices.

ii) Gravity frames provide increased recentering stiffness. When these were considered in the model, floor accelerations decreased further, and peak displacements decreased but were still greater than that of the as-designed structure. Most significantly, roof residual displacements reduced to approximately $50 \%$ of the as-designed structure not considering gravity frame effects.

iii) The combination of HF2V dissipators with gravity frames and well designed non-structural elements creates a system with almost no damage and low residual displacements. This system appears superior to conventional construction methods, particularly as it has the potential to result in less economic, financial and business impacts. 


\section{References}

Bradley, B. A., Dhakal, R. P., Mander, J. B., and Li, L. (2008). "Experimental multilevel seismic performance assessment of 3D RC frame designed for damage avoidance." Earthquake Engineering \& Structural Dynamics, 37(1), 1-20.

Building Seismic Saftey Council (BSSC). (2003). "National Earthquake Hazard Reduction Program (NEHRP) Recommended Provisions for Seismic Regulations for New Buildings and Other Structures - FEMA 450." prepared by the Building Seismic Safety Council (BSSC) for the Federal Emergency Management Agency (FEMA), Washington DC.

Cousins, W. J., and Porritt, T. E. (1993). "Improvements to lead-extrusion damper technology." Bulletin of the New Zealand National Society for Earthquake Engineering, 26(3), 342-348.

Desombre, J., Rodgers, G. W., MacRae, G. A., Rabczuk, T., Dhakal, R. P., and Chase, J. G. (2011). "Experimentally validated FEA models of HF2V damage free steel connections for use in full structural analyses." Journal of Structural Engineering \& Mechanics, 37(4), 385-399.

Kawashima, K., MacRae, G. A., Hoshikuma, J.-i., and Nagaya, K. (1998). "Residual displacement response spectrum." Journal of Structural Engineering, 124(5), 523530 .

Krawinkler, H., and Gupta, A. (1998). "Story Drift Demands for Steel Moment Frame Structures in Different Seismic Regions." Proc. 6th US National Conference on Earthquake Engineering, Seattle, Washington.

Li, L. (2006). "Further Experiments on Damage Avoidance design of Beam-tocolumn joints," Master of Engineering Thesis, University of Canterbury, Christchurch, New Zealand.

Limpert, E., Stahel, W. A., and Abbt, M. (2001). "Log-normal distributions across the sciences: Keys and clues." Bioscience, 51(5), 341-352.

Liu, J., and Astaneh-Asl, A. (2000). "Cyclic testing of simple connections including effects of slab." Journal of Structural Engineering, 126(1), 32-39.

Liu, J., and Astaneh-Asl, A. (2004). "Moment-rotation parameters for composite shear tab connections." Journal of Structural Engineering, 130(9), 1371-1380.

Luco, N. (2002). "Probabilistic Seismic Demand Analysis, SMRF Connection Fractures, And Near-Source Effects," PhD Dissertation, Stanford University.

MacRae, G. A., and Kawashima, K. (1997). "Post-earthquake residual displacements of bilinear oscillators." Earthquake Engineering \& Structural Dynamics, 26(7), 701716.

MacRae, G. A., Kimura, Y., and Roeder, C. (2004). "Effect of column stiffness on braced frame seismic behavior." Journal of Structural Engineering, 130(3), 381-391. 
Mander, J. B., and Cheng, C.-T. (1997). "Seismic Resistance Of Bridge Piers Based On Damage Avoidance Design." Technical Report NCEER-97-0014, U.S. National Center for Earthquake Engineering Research (NCEER), Department of Civil and Environmental Engineering, State University of New York at Buffalo, Buffalo, USA

Mander, T. J., Rodgers, G. W., Chase, J. G., Mander, J. B., MacRae, G. A., and Dhakal, R. P. (2009). "A Damage Avoidance Design Steel Beam-Column Moment Connection Using High-Force-To-Volume Dissipators." ASCE Journal of Structural Engineering, 135(11), 1390-1397.

Pekcan, G., Mander, J. B., and Chen, S. S. (1999). "Fundamental considerations for the design of non-linear viscous dampers." Earthquake Engineering and Structural Dynamics, 28(11), 1405-1425.

Robinson, W. H., and Greenbank, L. R. (1976). "Extrusion Energy Absorber Suitable For The Protection Of Structures During An Earthquake." Earthquake Engineering \& Structural Dynamics, 4(3), 251-259.

Rodgers, G. W., Chase, J. G., Mander, J. B., Leach, N. C., and Denmead, C. S. (2007). "Experimental development, tradeoff analysis and design implementation of high force-to-volume damping technology." Bulletin of the New Zealand Society for Earthquake Engineering, 40(2), 35-48.

Rodgers, G. W., Mander, J. B., Chase, J. G., Dhakal, R. P., Leach, N. C., and Denmead, C. S. (2008a). "Spectral analysis and design approach for high force-tovolume extrusion damper-based structural energy dissipation." Earthquake Engineering \& Structural Dynamics, 37(2), 207-223.

Rodgers, G. W., Solberg, K. M., Mander, J. B., Chase, J. G., Bradley, B. A., Dhakal, R. P., and Li, L. (2008b). "Performance Of A Damage-Protected Beam-Column Subassembly Utilizing External HF2V Energy Dissipation Devices." Earthquake Engineering \& Structural Dynamics, 37(13), 1549-1564.

Skinner, R. I., Robinson, W. H., and McVerry, G. H. (1993). An introduction to seismic isolation, Wiley, Chichester ; New York.

Somerville, P., Smith, N., Punyamurthula, S., and Sun, J. (1997). "Development of Ground Motion Time Histories For Phase II Of The FEMA/SAC Steel Project, SAC Background Document Report SAC/BD-97/04."

Tagawa, H., Macrae, G. A., and Lowes, L. (2007). "Evaluation of Seismic Response of Multi-Story Structures Using Dynamic Stability Coefficients - Continuous Column Effects in Steel Moment Frames in Perspective of Dynamic Stability." Journal of Structural and Constructional Engineering, Transactions of the Architectural Institute of Japan, AIJ, No.618, 57-64. 